\title{
B-type natriuretic peptide and glycaemia: an emerging cardiometabolic pathway?
}

\author{
P. Welsh • J. J. McMurray
}

Received: 14 December 2011 / Accepted: 1 February 2012/Published online: 8 March 2012

(C) Springer-Verlag 2012

\begin{abstract}
There is emerging evidence of cross-talk between the myocardium and systemic metabolic pathways. In particular, there is interest in the potential metabolic effects of A-type and B-type natriuretic peptides (ANP and BNP), produced in the myocardial tissue in response to ventricular stretch and cardiac overload. This commentary provides an overview of the evidence that natriuretic peptides promote lipolysis and enhance adiponectin production. In addition, we review new and existing evidence that BNP may directly improve glucose control, or else lower glucose indirectly via enhanced capillary permeability or greater renal excretion. Further investigation of the links between natriuretic peptide and glycaemia would seem important given the potential to reveal novel mechanisms to treat diabetes.
\end{abstract}

Keywords Adiponectin · ANP. BNP. Diabetes ·

Glycaemia · Insulin sensitivity IVGTT · Lipolysis .

Natriuretic peptides

\section{Abbreviations \\ ANP A-type natriuretic peptide \\ BNP B-type natriuretic peptide}

It has been known for 50 years that heart failure patients suffer from chronically elevated catecholamines [1], which alter glucose metabolism by depressing insulin secretion and increasing glycogenolysis and gluconeogenesis, thus resulting in hyperglycaemia [2]. Perhaps it is not entirely surprising, then, that B-type natriuretic peptide (BNP) and A-type

\section{P. Welsh $(\bowtie) \cdot$ J. J. McMurray}

BHF Glasgow Cardiovascular Research Centre, Institute of

Cardiovascular and Medical Sciences, University of Glasgow,

Glasgow G12 8TA, Scotland, UK

e-mail: Paul.Welsh@glasgow.ac.uk natriuretic peptide (ANP), which are produced in response to cardiac stress and mechanical stretch of the myocardium and are physiological antagonists of the renin-angiotensin system, might also play a role in energy metabolism. The potential role for these peptides in metabolic pathways has already been the subject of intense interest, as both BNP and ANP are known to be potent stimulators of lipolysis in adipose tissue $[3,4]$.

Relatively little is known regarding the role of natriuretic peptides in glucose metabolism. Natriuretic peptide receptors are present in human pancreatic alpha cells [5], although the physiological significance of this is not well understood. Investigations of the effect of ANP infusion on glucose metabolism go back to the 1980s [6]. Administration of ANP appears to increase circulating insulin [6], perhaps partly because ANP may be a substrate for insulindegrading enzyme [7]. A recent crossover study in ten fasting, healthy young men found that a high-dose ANP infusion stimulated a moderate increase in circulating glucose [8]. Of potential relevance, any lipolytic effect of natriuretic peptides might be expected to contribute to a reduction in insulin sensitivity. Thus, there are several strands of evidence that ANP may have some contextdependent influence on glucose metabolism, although these strands are disparate and any effect of BNP on glucose metabolism is even less clear.

In this issue of Diabetologia, Heinisch and co-authors describe a study of the effects of short-term infusion of BNP on circulating glucose, insulin and C-peptide concentrations during an IVGTT [9]. The study involved ten healthy male volunteers who received both BNP and placebo, infused for $1 \mathrm{~h}$ prior to and during the IVGTT, in random order using a single-blinded crossover design.

BNP infusion lowered the circulating glucose concentration by $12 \%$ during the first $10 \mathrm{~min}$ of the IVGTT 
(114 mmol/l during BNP infusion vs $130 \mathrm{mmol} / \mathrm{l}$ during placebo). There was a corresponding $13 \%$ drop in C-peptide concentration, indicating an appropriate beta cell response. The authors attributed the initial fall in glucose to a $19 \%$ increase in its volume of distribution in response to BNP. This explanation is consistent with evidence that capillary walls might be a barrier to glucose transport to interstitial spaces [10] and natriuretic peptides may increase capillary permeability [11]. There may, however, be other explanations. Pre-infusion of BNP may have stimulated diuresis and urinary glucose loss [12, 13] (unfortunately, urinary glucose was not measured in the study by Heinisch and co-workers [9]). It is of note that the circulating BNP level achieved following infusion was extremely high ( $\sim 400 \mathrm{pg} / \mathrm{ml}$; a concentration normally consistent with heart failure), perhaps increasing the likelihood of an appreciable diuretic effect even over the short term. Alternatively, the vasodilatory action of BNP may have increased skeletal muscle blood flow and uptake of glucose; the slightly higher heart rate on BNP might be attributable to increased catecholamine release. Even short-term administration of BNP suppresses the renin-angiotensin system, which in turn probably influences glucose-insulin homeostasis.

What might these findings tell us about the potential role of BNP in insulin resistance and diabetes? It is hard to give specific conclusions in this regard because of the participants studied and the very short-term exposure to BNP.

The fit young men studied, with a mean BMI of $23 \mathrm{~kg} / \mathrm{m}^{2}$, probably had near optimal insulin sensitivity, making it difficult to show any improvement, particularly given the small size of the study. Investigation of the effect of BNP on insulin sensitivity in individuals with impaired glucose tolerance or frank diabetes would be of interest now that data on healthy participants are available.

Studies of longer term elevation of BNP (and other natriuretic peptides) would also be of much more interest from a pathophysiological and therapeutic perspective. Other observations support the need for such studies. In a recent study of a relatively healthy community cohort, moderate elevations in natriuretic peptides were associated with a lower risk of type 2 diabetes [14]. Data from Mendelian randomisation studies also suggest that moderate lifelong elevations of BNP protect

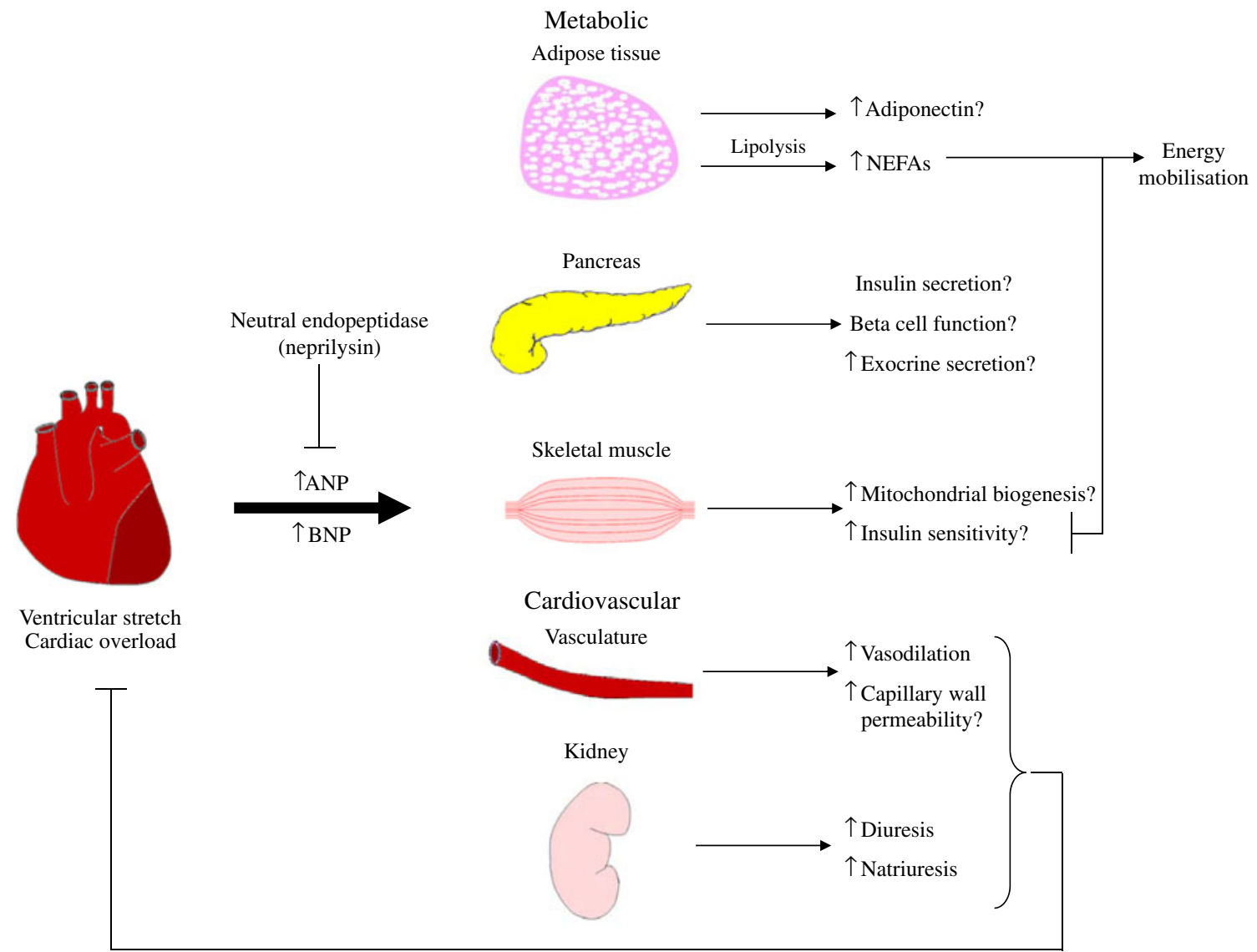

Fig. 1 Overview of some of the complex downstream potential metabolic and cardiovascular effects of natriuretic peptides on various tissues. Arrows indicate, where evidence is available, an increase or decrease in the physiological effect. Question marks denote relative uncertainty with regard to the current weight of evidence. The net effect of natriuretic peptide production might be to enhance glucose control, at least in some patient groups, although lipolytic effects may impinge upon any benefit to insulin sensitivity in the long term 
against type 2 diabetes [15]. Conversely, in cohorts comprising individuals in relatively good cardiovascular health, those who are obese or who clearly have increased insulin resistance and an elevated risk of diabetes also have reduced natriuretic peptide levels [16]. Animal models also support the notion that chronic changes in natriuretic peptides might modulate insulin-glucose homeostasis. Transgenic mice overexpressing the gene encoding BNP were protected from diet-induced insulin resistance and obesity, compared with wild-type mice, as a result of mitochondrial biogenesis [17]. Of further interest, BNP is known to have a strong positive correlation with adiponectin [18] and possibly stimulates its release from adipose tissue [19]. Whilst this link could also account for a lower diabetes risk, the role of adiponectin in insulin sensitivity in man remains uncertain. This BNP-adiponectin link could also, at least partially, explain the association between higher adiponectin levels and an elevated risk of mortality and morbidity in some cohorts [18, 20, 21].

How could longer term studies to investigate the effect of BNP on glucose metabolism be carried out? One approach might be to use orally active compounds that inhibit natriuretic peptide breakdown. Neprilysin is a neutral endopeptidase that degrades ANP and BNP, and orally acting neprilysin inhibitors are available for both experimental and human use [22-24]. Given the evidence from Mendelian randomisation studies, neprilysin inhibitors (as well as being antihypertensives) may be beneficial for diabetic patients and patients with impaired glucose tolerance in improving insulin sensitivity. Further Mendelian randomisation studies may also help tease apart causal pathways.

Hopefully the work of Heinisch et al will help stimulate more research on the role of natriuretic peptides in systemic glucose control. Collectively, these observations highlight the bidirectional relationships between metabolic and cardiovascular disease and the potential pathways underpinning these relationships (Fig. 1). The need to better understand the mechanisms underlying these relationships is clear, particularly the potential for manipulation of the pathways involved for the benefit of specific patient groups.

Acknowledgements We thank N. Sattar, University of Glasgow, for critical discussion of the manuscript.

Funding P. Welsh is supported by a British Heart Foundation fellowship grant (FS/10/005/28147).

Duality of interest The authors declare that there is no duality of interest associated with this manuscript.

Contribution statement Both PW and JJM were responsible for the conception and design of the manuscript, drafting the article and revising it critically for important intellectual content. Both authors approved the version to be published.

\section{References}

1. Chidsey CA, Harrison DC, Braunwald E (1962) Augmentation of the plasma nor-epinephrine response to exercise in patients with congestive heart failure. N Engl J Med 267:650-654

2. Mizock BA (1995) Alterations in carbohydrate metabolism during stress: a review of the literature. Am J Med 98:75-84

3. Birkenfeld AL, Budziarek P, Boschmann M et al (2008) Atrial natriuretic peptide induces postprandial lipid oxidation in humans. Diabetes 57:3199-3204

4. Polak J, Kotrc M, Wedellova Z et al (2011) Lipolytic effects of B-type natriuretic peptide 1-32 in adipose tissue of heart failure patients compared with healthy controls. J Am Coll Cardiol 58:1119-1125

5. Burgess MD, Moore KD, Carter GM et al (2009) C-type natriuretic peptide receptor expression in pancreatic alpha cells. Histochem Cell Biol 132:95-103

6. Uehlinger DE, Weidmann P, Gnadinger MP et al (1986) Increase in circulating insulin induced by atrial natriuretic peptide in normal humans. J Cardiovasc Pharmacol 8:1122-1129

7. Muller D, Schulze C, Baumeister H, Buck F, Richter D (1992) Rat insulin-degrading enzyme: cleavage pattern of the natriuretic peptide hormones ANP, BNP, and CNP revealed by HPLC and mass spectrometry. Biochemistry 31:11138-11143

8. Birkenfeld AL, Boschmann M, Moro C et al (2006) $\beta$-Adrenergic and atrial natriuretic peptide interactions on human cardiovascular and metabolic regulation. J Clin Endocrinol Metab 91:5069-5075

9. Heinisch BB, Vila G, Resl M et al (2012) B-type natriuretic peptide (BNP) affects the initial response to intravenous glucose: a randomised placebo-controlled cross-over study in healthy men. Diabetologia. doi:10.1007/s00125-011-2392-1

10. Muller M, Holmang A, Andersson OK, Eichler HG, Lonnroth $P$ (1996) Measurement of interstitial muscle glucose and lactate concentrations during an oral glucose tolerance test. Am J Physiol 271(6 Pt 1):E1003-E1007

11. McKay MK, Huxley VH (1995) ANP increases capillary permeability to protein independent of perfusate protein composition. Am J Physiol 268:H1139-H1148

12. Jensen KT, Carstens J, Pedersen EB (1998) Effect of BNP on renal hemodynamics, tubular function and vasoactive hormones in humans. Am J Physiol 274:F63-F72

13. Kaneko JJ, Mattheeuws D, Rottiers RP, van Der Stock J, Vermeulen A (1978) The effect of urinary glucose excretion on the plasma glucose clearances and plasma insulin responses to intravenous glucose loads in unanaesthesized dogs. Acta Endocrinol (Copenh) 87:133-138

14. Salomaa V, Havulinna A, Saarela O et al (2010) Thirty-one novel biomarkers as predictors for clinically incident diabetes. PLoS One 5:e10100

15. Pfister R, Sharp S, Luben R et al (2011) Mendelian randomization study of B-type natriuretic peptide and type 2 diabetes: evidence of causal association from population studies. PLoS Med 8:e1001112

16. Khan AM, Cheng S, Magnusson M et al (2011) Cardiac natriuretic peptides, obesity, and insulin resistance: evidence from two community-based studies. J Clin Endocrinol Metab 96:3242-3249

17. Miyashita K, Itoh H, Tsujimoto H et al (2009) Natriuretic peptides/ cGMP/cGMP-dependent protein kinase cascades promote muscle mitochondrial biogenesis and prevent obesity. Diabetes 58:2880-2892

18. Wannamethee SG, Welsh P, Whincup PH et al (2011) High adiponectin and increased risk of cardiovascular disease and mortality in asymptomatic older men: does NT-proBNP help to explain this association? Eur J Cardiovasc Prev Rehabil 18:65-71

19. Tsukamoto O, Fujita M, Kato M, Yamazaki S, Asano Y, Ogai A et al (2009) Natriuretic peptides enhance the production of adiponectin in human adipocytes and in patients with chronic heart failure. J Am Coll Cardiol 53:2070-2077 
20. Ang DS, Welsh P, Watt P, Nelson SM, Struthers A, Sattar N (2009) Serial changes in adiponectin and BNP in ACS patients: paradoxical associations with each other and with prognosis. Clin Sci (Lond) 117:41-48

21. Schnabel R, Messow CM, Lubos E et al (2008) Association of adiponectin with adverse outcome in coronary artery disease patients: results from the AtheroGene study. Eur Heart J 29:649657

22. Kenny AJ, Bourne A, Ingram J (1993) Hydrolysis of human and pig brain natriuretic peptides, urodilatin, $\mathrm{C}$-type natriuretic peptide and some C-receptor ligands by endopeptidase-24.11. Biochem J 291:83-88

23. Gu J, Noe A, Chandra P et al (2010) Pharmacokinetics and pharmacodynamics of LCZ696, a novel dual-acting angiotensin receptor-neprilysin inhibitor (ARNi). J Clin Pharmacol 50:401414

24. Chen HH, Cataliotti A, Burnett JC Jr (2001) Role of the natriuretic peptides in the cardiorenal and humoral actions of omapatrilat: insights from experimental heart failure. Curr Hypertens Rep 3 (Suppl 2):S15-S21 